\title{
Biosynthesis of lemongrass essential oil and the underlying mechanism for its insecticidal activity
}

Mohammad Mukarram*, M. Masroor A. Khan, Andleeb Zehra, Sadaf Choudhary, Tariq Aftab, M. Naeem

Advance Plant Physiology Section, Department of Botany, Aligarh Muslim University, Aligarh, India

\begin{abstract}
Lemongrass (Cymbopogon flexuosus) is an aromatic perennial grass grown extensively for its essential oil. Lemongrass oil is chiefly a mixture of various cyclic and acyclic bioactive monoterpenes. We reviewed lemongrass oil and its biosynthesis in the present chapter along with its biochemical composition. Furthermore, we attempted to explore both the possible routes for essential oil biosynthesis in lemongrass, i.e. mevalonate and non-mevalonate pathways and how these pathways interwind with each other. Lemongrass oil has high commercial potential in medicinal, cosmetic, food and energy industries. Regarding the pharmacological properties, a wide array of biological activities has been observed in lemongrass oil such as antimicrobial, insecticidal, analgesic and anti-cancer properties as well as its efficacy as insect-repellent. The later sections were dedicated for the analysis of insecticidal property of the lemongrass oil and the mechanism working behind this phenomenon where it was observed that in addition to synergistic effects, various components of lemongrass oil can also induce specific neurotoxic and cytotoxic responses in the insects.
\end{abstract}

Keywords: Citral, essential oil, integrated pest management, insect-repellent, lemongrass, MEP pathway, mevalonate pathway.

*Corresponding author

Correspondence to: mdmukarram007@gmail.com 


\section{Introduction}

Lemongrass (Cymbopogon flexuosus) is a perennial crop from grass family Poaceae with numerous industrial applications. The term lemongrass is coined after its 'lemony' essence. Lemongrass is endogenous to India, Sri Lanka, Brazil and Myanmar. India is a major exporter of lemongrass among these with an exportation capacity of about 1000 tons worldwide every year, predominantly to America, England, Australia (Ganjewala and Gupta, 2013).

Lemongrass is chiefly grown for its essential oil (EO) that has multiple medicinal (anticancer, analgesic and antimicrobial) and cosmetic usage (Chandrashekar and Prasanna, 2010; Ganjewala, 2009). In addition to this, lemongrass is a rich source of Vitamins A, B-complex, C, Folate and mineral nutrients including magnesium phosphorous, manganese, copper, potassium, calcium, zinc and iron. It is also used in Thai cuisine as well as in the form of herbal tea (Figure 1). Recent developments have also explored lemongrass as biofuels enhancing its worth even more (Dhinesh et al., 2016; Alagumalai, 2015). In addition

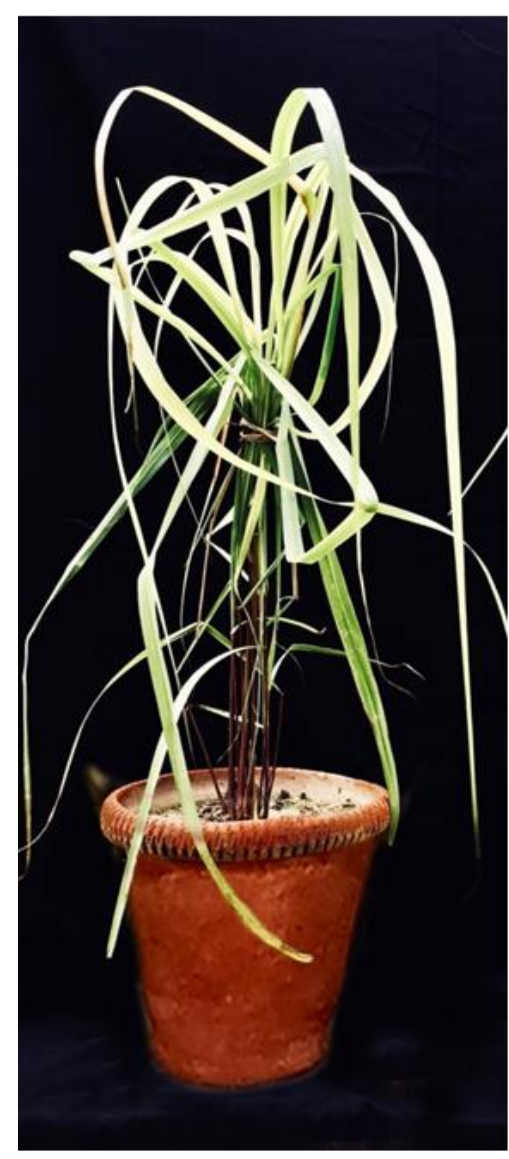

Figure 1. A 150-days-old Lemongrass (Cymbopogon flexuosus) plant in the pot. to these, lemongrass essential oil has extensive utilisation in the synthesis of eco-friendly pesticides because of its insect-repellent nature (Zheljazkov et al., 2011; Ganjewala, 2009). Given the high amount of plant volatiles, lemongrass oil has also been used in the making of high-grade deodorant or air fresheners (Srivastava et al., 2013).

\section{Lemongrass Essential Oil}

In principle, plants synthesise essential oils (EOs) for defence and communication (Hassoun and Çoban, 2017; Pavela and Benelli, 2016). They provide defence against multiple phenomena including but not limited to bacteria, virus, fungi and insects (Swamy et al., 2016; Vergis et al., 2015). Due to these, EOs find high use in pharmaceutical, cosmetic and food industries. As of now, almost 10-15\% of total about 3000 different EOs are being used on a commercial scale for various purposes (Hassoun and Çoban, 2017). The EOs have a strong 
flavour or essence and thus are called as 'essential' oils. This property of EOs is highly exploited by perfumery and flavour industries (Pavela and Benelli, 2016).

Lemongrass EO is one from about 400-500 commercially produced EOs (Tisserand and Young, 2013). Lemongrass EO has rich spectra of compounds enriched with rigorous medicinal properties, e.g. antibacterial, antiviral, antifungal, antifungal, anticancer and antitumor (Sharma et al., 2009). It also has limonene and borneol that are attributed for analgesic and anaesthetic properties (Sharma et al., 2009). However, other closely related species to lemongrass do not have the identical chemical composition of their EOs. Cymbopogon flexuous is an aldehyde type grass and mainly contains citral (60-80\%) which is an isomeric mixture of neral and geranial (higher in quantity than neral) (Abdulazeez et al., 2016; Kakarla and Ganjewala, 2009). This citral content can be used as a quality marker for lemongrass EO (Abdulazeez et al., 2016). Remaining constituents are elemol, geraniol, geranyl acetate, nerol, isoneral, citronellal, isogeranial citronellyl acetate which together make up about 10-20\% of lemongrass EO. Other related species are Cymbopogon winterianus (Java citronella) and Cymbopogon martinii (Palmarosa). These species are distinguished for their comparatively higher alcohol (e.g. nerol and geraniol) content than lemongrass (Meena et al., 2016). Java citronella is an intermediate type, i.e. both aldehyde and alcohol are found in moderation while Palmarosa is an alcohol type, i.e. it has more alcohol than aldehyde (Meena et al., 2016).

\section{Essential Oil Biosynthesis in Lemongrass}

Biosynthesis of monoterpenes has been a point of interest since long (Banthrope et al., 1980, 1972; Croteau, 1988, 1987). Various approaches were adopted with the advent of technology, including the use of radioactive compounds (Ganjewala and Luthra, 2007a). Though these attempts provided significant insights, essential oil biosynthesis in lemongrass could not be entirely comprehended and still has research gaps.

The essential oil in lemongrass is primarily a mixture of cyclic and acyclic monoterpenes which are chiefly derived from geranyl diphosphate (GPP) which acts as the precursor for monoterpenes biosynthesis (Ganjewala and Gupta, 2013). The GPP is formed by the condensation of isopentenyl diphosphate (IPP) and dimethylallyl diphosphate (DMAPP) units. This IPP can either be synthesised in the plastid (MEP-pathway) or in the cytoplasm (MVApathway). The IPP units generated by MVA-pathway could be transferred to plastids for synthesising monoterpenes along with other IPP units generated through MEP-pathway. 
Therefore, essential oil biosynthesis in lemongrass leaves occurs either through cytoplasmicMVA pathway or through the plastidic-MEP pathway (Ganjewala and Gupta, 2013).

\section{Mevalonate Pathway}

In the first step of acetate-MVA pathway, two acetyl-CoA molecules condense to generate acetoacetyl-CoA. This condensation is catalysed by acetoacetyl-CoA thiolase enzyme (E.C. 2.3.1.9). In the second reaction step, acetoacetyl-CoA is further condensed into 3-hydroxymethylglutaryl-CoA (HMG-CoA) through HMG-CoA synthase (E.C. 2.3.3.10) with the addition of another acetyl-CoA molecule. HMG-CoA is then reduced into mevalonate (MVA) by HMG-CoA reductase (E.C. 1.1.1.34). Mevalonate plays a crucial role in the MVA pathway by acting as a precursor for the biosynthesis of IPP units.

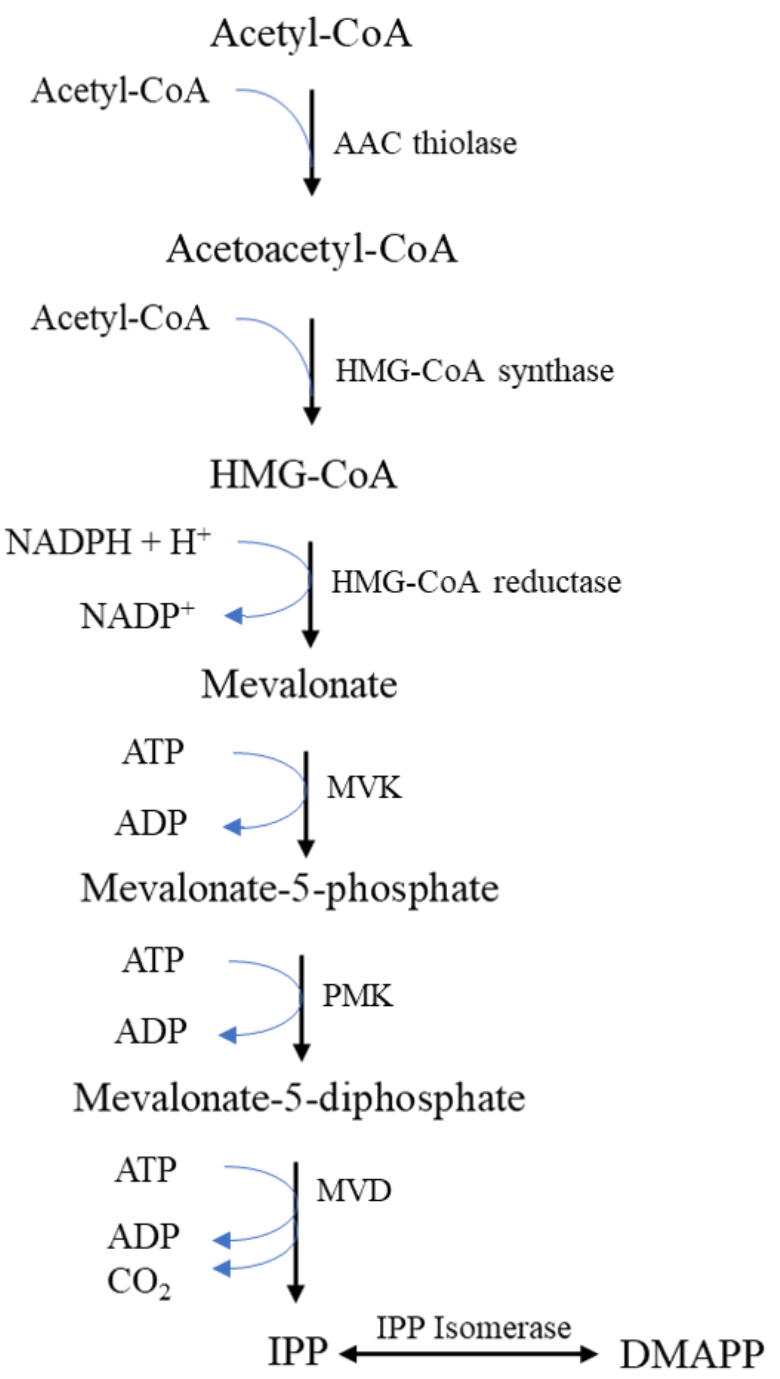

Figure 2. Mevalonate pathway for the biosynthesis of IPP and DMAPP. AAC thiolase, acetoacetyl coenzyme A thiolase; HMG-CoA, 3-hydroxy-methylglutaryl coenzyme A; MVK, 
mevalonate kinase; PMK, phosphomevalonate kinase; MVD, mevalonate-5-diphosphate decarboxylase; IPP, isopentenyl diphosphate; DMAPP, dimethylallyl diphosphate.

Final steps can be marked as the generation of IPP units from MVA. However, this conversion is a multi-step process which includes phosphorylation and decarboxylation of mevalonate. Mevalonate kinase or MVK (E.C. 2.7.1.36) catalyses the phosphorylation of mevalonate into mevalonate-5-phosphate which is further phosphorylated into mevalonate-5-diphosphate (MVAPP) by phosphomevalonate kinase or PMK (E.C. 2.7.4.2). Subsequent decarboxylation of mevalonate-5-diphosphate through mevalonate-5-diphosphate decarboxylase or MVD (E.C. 4.1.1.33) generates IPP units. (Figure 2)

\section{Mevalonate-independent Pathway (MEP Pathway)}

The MVA pathway was considered to be the only pathway for IPP biosynthesis in plants until an alternate non-mevalonate pathway was discovered (Rohmer, 1999). This mevalonateindependent pathway, also known as the MEP pathway starts with the conversion of glyceraldehyde 3-phosphate and pyruvate to 1-deoxy-xylulose-5-phosphate (DXP) (Richard et al., 2001). This conversion is catalysed by DXP synthase (E.C. 4.1.3.37) (Grawert et al., 2011). DXP reductoisomerase (E.C. 1.1.1.267) then rearrange DXP into a branched intermediate aldose with the subsequent formation of 2-C-methyl-D-erythritol-4-phosphate (MEP) (Grawert et al., 2011). In the third reaction step, MEP cytidyltransferase (E.C. 2.7.7.60) converts MEP into 4-diphosphocytidyl-2-C-methyl-D-erythritol (CDP-ME) (Kuzuyama, 2002). CDP-ME kinase or CMK (E.C. 2.7.1.148) catalyses the phosphorylation of CDP-ME through the transfer of a phosphate residue provided by ATP. The subsequent product (CDP-ME 2-phosphate or CDP-MEP) in the fifth reaction step is further converted into 2-C-methyl-D-erythritol 2,4cyclodiphosphate (MEcPP) through intramolecular transphosphorylation. This step is catalysed by MEcPP synthase or MCS (E.C. 4.6.1.12). In the sixth reaction step, MEcPP is converted into 1-hydroxy-2-methyl-2-(E)-butenyl 4-diphosphate (HMBPP) through HMBPP synthase or HDS (E.C. 1.17.4.3). In the final step of IPP formation, HMBPP is further to a mixture of IPP and its isomer DMAPP by the enzyme HMBPP reductase or HDR enzyme (E.C.

\subsubsection{2). (Figure 3)}




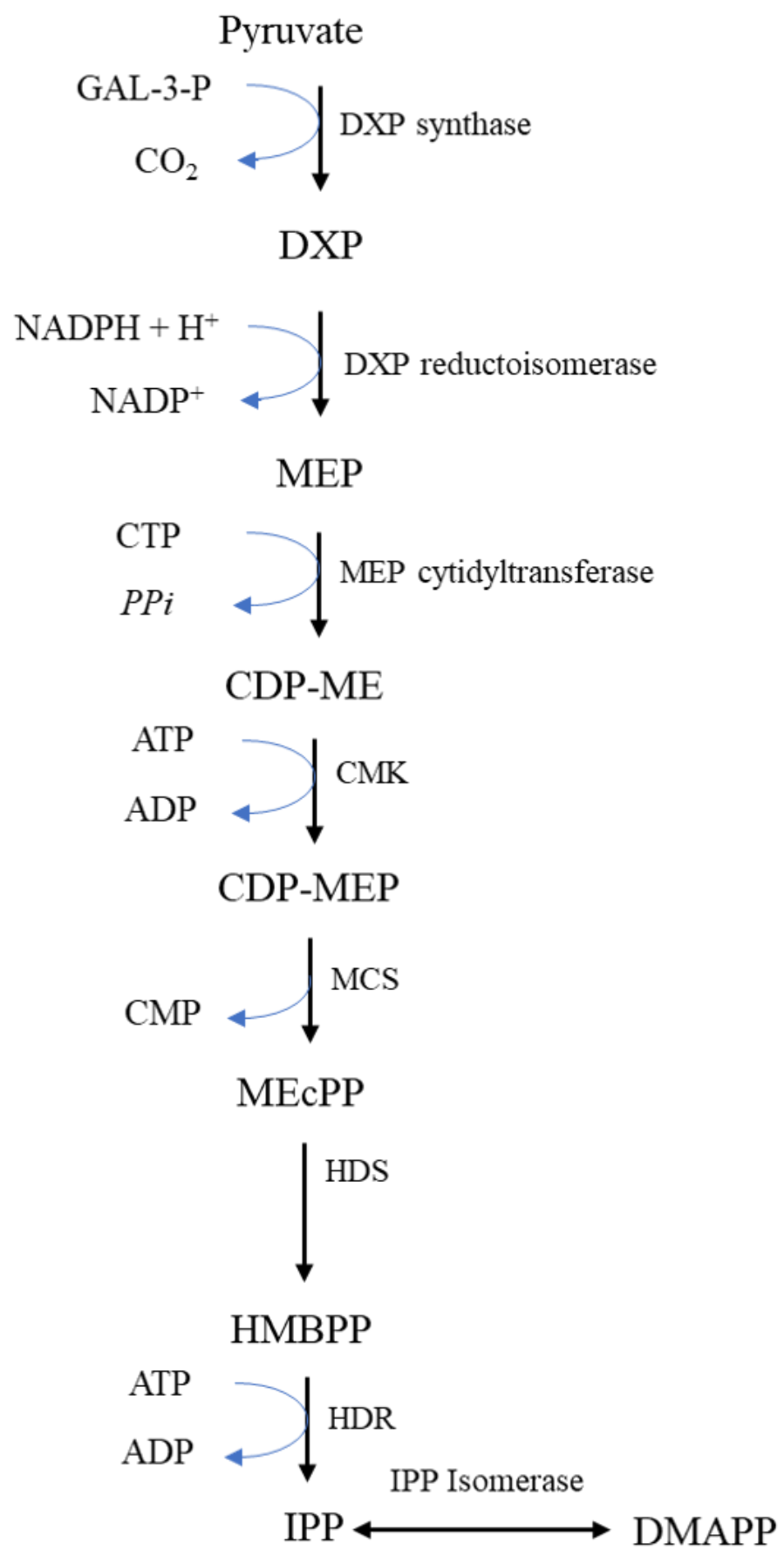

Figure 3. Mevalonate independent pathway (MEP pathway) for the biosynthesis of IPP and DMAPP. GAL-3-P, glyceraldehyde 3-phosphate; DXP, 1-deoxy-xylulose-5-phosphate; MEP, 2-C-methyl-D-erythritol-4-phosphate; CDP-ME, 4-diphosphocytidyl-2-C-methyl-Derythritol; CMK, 4-diphosphocytidyl-2-C-methyl-D-erythritol kinase; CDP-MEP, 4diphosphocytidyl-2-C-methyl-D-erythritol-2-phosphate; MCS, 2-C-methyl-D-erythritol 2,4cyclodiphosphate synthase; MEcPP, 2-C-methyl-D-erythritol 2,4-cyclodiphosphate; HDS, 1hydroxy-2-methyl-2-(E)-butenyl 4-diphosphate synthase; HMBPP, 1-hydroxy-2-methyl-2(E)-butenyl 4-diphosphate; HDR, 1-hydroxy-2-methyl-2-(E)-butenyl 4-diphosphate reductase; IPP, isopentenyl diphosphate; DMAPP, dimethylallyl diphosphate. 
The IPP generated through the MVA pathway as well as through MEP pathway is converted to produce GPP by GPP synthase or GPS (E.C. 2.5.1.1). All the cyclic and acyclic monoterpenes present in the lemongrass essential oil, e.g. geranial, neral and citronellal are produced by GPP through different reactions. (Figure 4)

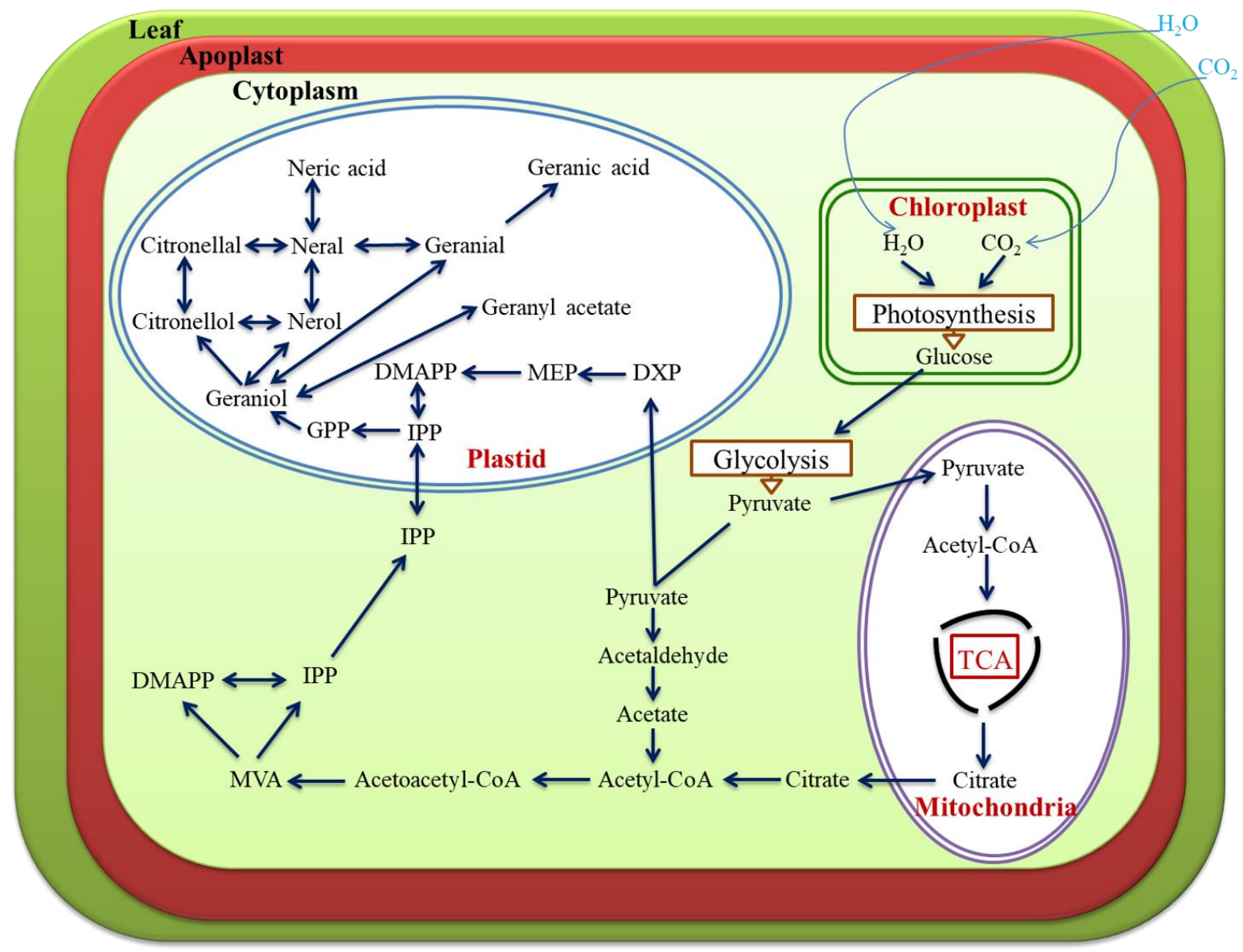

Figure 4. Demonstrative representation for essential oil biosynthesis through MVA and MEP pathways and their interaction with other metabolic processes in the lemongrass. DMAPP: dimethylallyl diphosphate, MEP: 2-C methylerythritol 4-phosphate, DXP: 1-deoxyD-xylulose-5-phosphate, GPP: geranyl diphosphate, IPP: isopentenyl diphosphate MVA: mevalonate.

\section{Essential Oil Storage}

Lemongrass plant stores EO in its leaf parenchymal cells which are also known as 'oil cells' (Ganjewala and Gupta 2013). Expanding lemongrass leaves synthesise EO more rapidly during the early days of their development. Acetylation potential is also on the peek at this stage. This renders higher content of geranyl acetate and citronellyl acetate than geraniol and citronellol, respectively. The cytosolic-MVA pathway is more active in younger leaves that explains higher 
EO content in young lemongrass leaves. In older leaves, geranyl acetate and citronellyl acetate content start to diminish as a result of negligible acetylation capacity (Ganjewala and Luthra 2007a). Moreover, the photosynthetic rate lowered down in older leaves that might further account for decreased yield (i.e. EO content) in the older lemongrass leaves (Maffei et al., 1988).

\section{Insecticidal Property of Lemongrass Essential Oil}

Our heavy dependence on chemical pesticides till date has posed serious health concerns over the decade. These pesticides are a serious threat to non-target hosts, including humans that might cause major setbacks in the ecological food web. Recent developments are more focused on searching sustainable insecticidal options and causing minimal side-effects and bioaccumulation. Essential oils have played a key role in the management of various insects of economic importance including pests, mites, mosquitoes and aphids (Feroz, 2020; Manh and Tuyet, 2020; Huong et al., 2019). Essential oils (EOs) are the volatile mixture extracted from various plant species which have cytotoxic potential and can be exploited as insecticides (AlSarar et al., 2020; Manh and Tuyet, 2020). Along with cytotoxicity, EOs are attributed to cause neurological damages and organ-failure in target organisms (Afify et al., 2019). Other sublethal effects can include irritation, repellence and complications in reproduction and proliferation (Muturi et al., 2020). Essential oils can induce detrimental responses in storedproduct insects by entering into their digestive system (Devi et al., 2019). Moreover, usage of EOs as insecticides is garnering attention because of their non-toxicity to non-target hosts, inexpensiveness, biodigestibility and negligible bioaccumulation (Eden et al., 2020).

Essential oils from lemongrass family (Cymbopogon spp.) have been reported highly effective against various diseases of animals, plants as well as of processed and stored food products caused by insects and other related organisms, e.g. mites (Li et al., 2020; Devi et al., 2019). The insecticidal property of lemongrass EO is accredited to the various bioactive cyclic and acyclic terpenes constituents present in its oil (Eden et al., 2020) (Table 1). Citral (i.e. a mixture of geranial and neral) is considered to be the key contributor for the insecticidal property of lemongrass EO (Eden et al., 2020; Solomon et al., 2012). It was also found to impart sub-lethal responses on larval growth and production of the cabbage looper (Tak and Isman, 2016). 
Table 1. Chemical composition of lemongrass (Cymbopogon flexuosus (Steud.) Wats) essential oil collected in Aligarh, India. The compositional analysis of essential oil was carried out by gas chromatography-mass spectrometry (GCMS- Shimadzu QP-2010 Plus) with Thermal Desorption System TD 20.

\begin{tabular}{|c|c|c|c|c|c|}
\hline No. & $\begin{array}{c}\text { Retention } \\
\text { Time } \\
\text { (min) }\end{array}$ & $\begin{array}{c}\text { Molecular } \\
\text { Formula }\end{array}$ & $\begin{array}{c}\text { Molecular } \\
\text { Mass }\end{array}$ & Compound & $\begin{array}{l}\text { Abundance } \\
\text { in EO (\%) }\end{array}$ \\
\hline 1. & 7.433 & $\mathrm{C}_{10} \mathrm{H}_{16}$ & 136 & $\alpha$-Pinene & 0.08 \\
\hline 2. & 8.020 & $\mathrm{C}_{10} \mathrm{H}_{16}$ & 136 & Camphene & 0.48 \\
\hline 3. & 9.488 & $\mathrm{C}_{8} \mathrm{H}_{14} \mathrm{O}$ & 126 & 6-methyl-5-hepten-2-one & 0.19 \\
\hline 4. & 11.250 & $\mathrm{C}_{10} \mathrm{H}_{16}$ & 136 & Limonene & 0.83 \\
\hline 5. & 13.185 & $\mathrm{C}_{9} \mathrm{H}_{18} \mathrm{O}$ & 142 & Pentyl propyl ketone & 0.92 \\
\hline 6. & 14.529 & $\mathrm{C}_{10} \mathrm{H}_{18} \mathrm{O}$ & 154 & Linalool & 0.96 \\
\hline 7. & 16.444 & $\mathrm{C}_{10} \mathrm{H}_{16} \mathrm{O}$ & 152 & 6-octenal-7-methyl-3-methylene & 0.20 \\
\hline 8. & 16.622 & $\mathrm{C}_{10} \mathrm{H}_{18} \mathrm{O}$ & 154 & Chrysanthemol (trans)- & 0.54 \\
\hline 9. & 16.854 & $\mathrm{C}_{10} \mathrm{H}_{18} \mathrm{O}$ & 154 & Citronellal & 1.22 \\
\hline 10. & 17.301 & $\mathrm{C}_{10} \mathrm{H}_{16} \mathrm{O}$ & 152 & Isoneral & 1.11 \\
\hline 11. & 18.172 & $\mathrm{C}_{10} \mathrm{H}_{16} \mathrm{O}$ & 152 & Isogeranial & 1.49 \\
\hline 12. & 20.615 & $\mathrm{C}_{10} \mathrm{H}_{20} \mathrm{O}$ & 156 & Citronellol & 1.52 \\
\hline 13. & 21.051 & $\mathrm{C}_{10} \mathrm{H}_{16} \mathrm{O}$ & 152 & Neral & 28.20 \\
\hline 14. & 21.710 & $\mathrm{C}_{10} \mathrm{H}_{18} \mathrm{O}$ & 154 & Geraniol & 6.33 \\
\hline 15. & 22.504 & $\mathrm{C}_{10} \mathrm{H}_{16} \mathrm{O}$ & 152 & Geranial & 39.05 \\
\hline 16. & 25.803 & $\mathrm{C}_{12} \mathrm{H}_{22} \mathrm{O}_{2}$ & 198 & Citronellyl acetate & 0.87 \\
\hline 17. & 27.050 & $\mathrm{C}_{12} \mathrm{H}_{20} \mathrm{O}_{2}$ & 196 & Geranyl acetate & 2.46 \\
\hline 18. & 27.397 & $\mathrm{C}_{15} \mathrm{H}_{24}$ & 204 & $\beta$-Elemene & 0.60 \\
\hline
\end{tabular}




$\begin{array}{llllll}\text { 19. } & 28.586 & \mathrm{C}_{15} \mathrm{H}_{24} & 204 & (\text { E)-Caryophyllene } & 0.57 \\ \text { 20. } & 31.151 & \mathrm{C}_{15} \mathrm{H}_{24} & 204 & \text { Germacrene D } & 0.53 \\ \text { 21. } & 32.205 & \mathrm{C}_{15} \mathrm{H}_{24} & 204 & \beta \text {-Elemene } & 0.37 \\ \text { 22. } & 32.485 & \mathrm{C}_{15} \mathrm{H}_{24} & 204 & \gamma \text {-Cadinene } & 0.27 \\ \text { 23. } & 34.026 & \mathrm{C}_{15} \mathrm{H}_{26} \mathrm{O} & 222 & \alpha \text {-Elemol } & 5.85 \\ \text { 24. } & 35.033 & \mathrm{C}_{15} \mathrm{H}_{26} \mathrm{O} & 222 & \text { Germacrenol D } & 2.24 \\ \text { 25. } & 35.153 & \mathrm{C}_{15} \mathrm{H}_{24} \mathrm{O} & 220 & \text { Caryophyllene oxide } & 0.58 \\ \text { 26. } & 38.066 & \mathrm{C}_{15} \mathrm{H}_{26} \mathrm{O} & 222 & \text { Cadinenol } & 1.26 \\ \text { 27. } & 38.696 & \mathrm{C}_{15} \mathrm{H}_{26} \mathrm{O} & 222 & \alpha \text {-Elemol } & 1.25\end{array}$

\footnotetext{
* Essential Oil constituents were identified on the basis of their retention time (RT) during GCMS analysis and are listed according to their order of elution on the solid phase. Abundance $(\%)=$ Percent peak area of essential oil component.

In addition to its major constituent, minor EO components could also exhibit synergistic or antagonising effects in insects (Devi et al., 2019). Lemongrass essential oil comprises germacrene D (2.24\%), caryophyllene $(0.57 \%)$ and caryophyllene oxide $(0.58 \%)$ in limited quantity. These bioactive compounds, however, carry substantial insecticidal and repellent activities against various insects, including common housefly and malarial vector mosquitoes (Mokhtari et al., 2020). However, percentage abundance of these constituents can vary depending on the geography, temperature, plant developmental stage, method used for essential oil extraction as well as the solvent used for the extraction (Muturi et al., 2020). Given such dynamic composition, different responses or varying severity of such responses against the same insect can be exhibited by the essential oils (Al-Sarar et al., 2020). (Figure 5)
} 

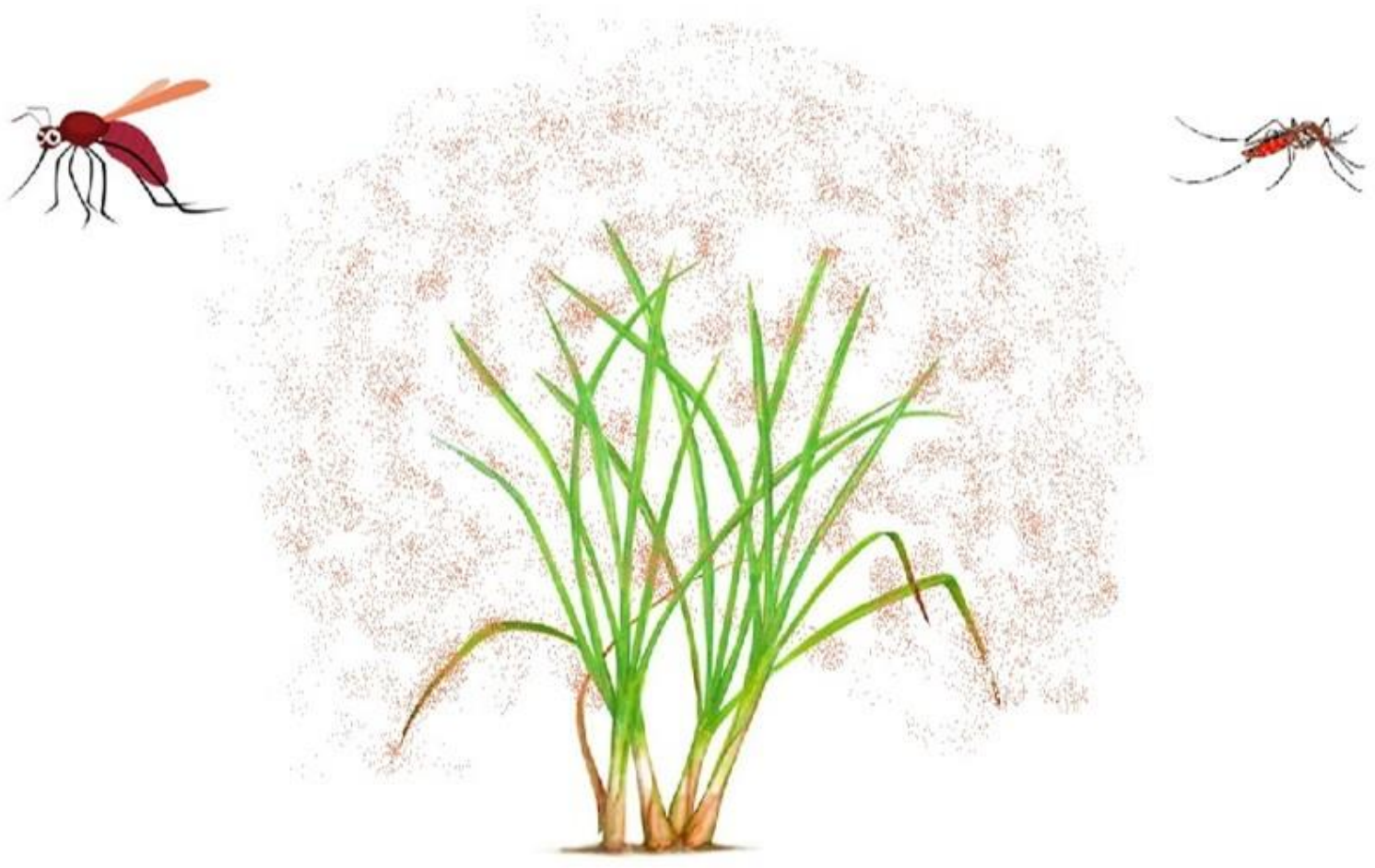

Figure 5. Lemongrass and its interaction with insects. The volatiles from lemongrass plant (orange plumes) consist a mixture of cyclic and acyclic monoterpenes that possess a pungent lemony smell with insect-repellent potential

\section{Mechanism for Insecticidal Activity}

Essential oils can act on different aspects of insect physiology. It could exhibit detrimental effects on the growth, development and reproduction as well as interfere with respiratory enzymes of mitochondrial membrane and insect nervous system itself (Feroz, 2020). Essential oils can easily enter into insect respiratory system given their highly volatile nature. Once in the respiratory system, bioactive components of EOs target olfactory receptors hijacking insect respiration (Devi et al., 2019). The activation of a subset of the olfactory receptor neurons by lemongrass EO has also been reported in the insect (Afify et al., 2019). Along with olfactory neurons, essential oils can incite other neurotoxic responses as well (Gaire et al., 2019; Politi et al., 2017). It can inhibit the activity of different neurotransmitters, including acetylcholine esterase and octopamine (Singh et al., 2017; Rajashekar et al., 2014; Price and Berry, 2006). Fumigant toxicity of EOs can interfere with insect metabolism and can exhibit a wide response range with lethal to sub-lethal impact including the reduction in the DNA synthesis rate (Feroz, 2020; Devi et al., 2019). These responses and neurotoxic efficiency of EOs is further assisted 
by the fact that EOs might ultimately have the potential to hijack various receptors associated with GABA pathway and neurotransmission such as octopamine and acetylcholine esterase receptors in insects (Manh et al., 2020).

Furthermore, EOs can also induce cytotoxicity in mitochondria and damage its membrane by reducing membrane potential through depolarisation (Feroz, 2020). This also alters the permeability of the mitochondrial membrane (Doll-Boscardin et al., 2012). Mitochondrial dehydrogenase activity and in turn, the overall mitochondrial metabolic rate could thus be reduced under EOs exposure (Feroz, 2020).

A major constituent in lemongrass EO, citral, can regulate cell proliferation by interacting with intracellular oxygen radicals and oxidative stress (Sanches et al., 2017; Kapur et al., 2016). Additionally, citral along with other EO components might act on neuroreceptors, hinder signal transduction, cause hormonal imbalance, membrane damage as well as cytotoxicity in the host (Feroz, 2020; Manh and Tuyet, 2020; Manh et al., 2020; Rattan, 2010). In addition to citral, different other components might target different sites in insect, enabling essential oils to attack multiple target sites simultaneously (Suwannavod et al., 2019). Components of EOs could exhibit a synergistic effect in insects, which further intensifies their insecticidal properties. Interestingly, insects can minimize the toxic effects of various major components through their defence and detoxification system (Scalerandi et al., 2018). However, the underrated minor components are the ones that could impart graver consequences in insects by evading their detoxification (Scalerandi et al., 2018). Such constituents can induce cytotoxicity in various insect cell lines, including ovarian cell line (Tak et al., 2016; Brari and Thakur, 2015).

Essential oils might also target specific vital metabolic enzymes. This can be correlated to various acidic phenolic components of EOs including geranial and neral, given their elicited reactivity with most enzyme active sites which can even lead to inactivation of the active sites (Ngongang et al., 2019). Phenoloxidase is one such enzyme that is considered as an important marker for insect defence system (Feroz, 2020; Huang et al., 2016). It provides resistance against various insecticides, and any change in its activity can be used to determine the toxicity level of any chemical (Bali and Kaur, 2013). Essential oils might interfere with the activation cascade of phenoloxidase and thus hampering its activity (Kalita and Devi, 2016). Such downregulation in phenoloxidase activity by EOs weakens insect immune system and exhibit serious damage to the insects in the long run. Similarly, lactate dehydrogenase activity was also found to be enhanced with EOs application (Qari et al., 2017). Lactate dehydrogenase 
activity is a potential marker for the evaluation of cellular damage and the enhancement in its concentration is directly proportional to the damage caused in the organism (Brown et al., 2012). It is thought that EOs might modulate the expression of genes associated with the biosynthesis of this enzyme (Qari et al., 2017).

Essential oils from different Cymbopogon spp. were also traced to hamper haemocyte viability in two different insect larvae populations (Feroz, 2020). Haemocytes are considered to have a significant part in maintaining the cellular and humoral immune system in insects (Kalita and Devi, 2016). Others (Kalita et al., 2017; Kalita and Devi, 2016) suggested that haemocytes viability can be modulated either by targeting constituents of insect immune systems or by regulating immune responses. Such alterations negatively influence the hematopoietic system along with the aberration in endocrine gland activity (Feroz, 2020). This retards overall insect growth and development.

Components of EOs can be effective against various insects to a different degree. Moreover, they can target different insect systems with varying intensity. These variations could be categorised into two possibilities: plant-dependent factors and insect-dependent factors. While the plant-dependent factors can be correlated with the varying concentration of EOs constituents, developmental stage of the plant along with various phenological and environmental conditions, the insect-dependent factors could comprise a level of EOs absorption by the insect as well as developmental stage, cuticle thickness and weight of the insect (Devi et al., 2019). Essential oils, which is a mixture of such components, thus can target the nervous system, respiratory system, reproduction system as well as the defence system in insects (Devi et al., 2019). Various recent reports have suggested that EOs can utilise neurological mechanism to impart substantial damage in insects (Moore, 2014; Kain et al., 2013; Hamid et al., 2011; Isman, 2006).

\section{Conclusion and Future Perspective}

Lemongrass plant is mainly cultivated for its essential oil that has numerous pharmacological and industrial applications. Apart from its heavy use in cosmetics and food industries, lemongrass oil has substantial potential in the synthesis of environment-friendly insecticides. Essential oil constituents of lemongrass have a wide spectrum of biological activities. These components could also exhibit cytotoxic as well as neurotoxic response in different insects of 
economic importance. However, the full potential of lemongrass EO has not still reached. Much research could be performed to:

1. Synthesise more potent insecticides from lemongrass EO.

2. Enhance the longevity and durability of such herbal insecticides.

3. Exploit the cytotoxic nature of lemongrass EO in the treatment of human diseases such as the tumour. 


\section{References}

Abdulazeez, M. A., Abdullahi, A. S., \& James, B. D. (2016). Lemongrass (Cymbopogon spp.) oils. In Essential oils in food preservation, flavor and safety (pp. 509-516). Academic Press.

Afify, A., Betz, J. F., Riabinina, O., Lahondère, C., \& Potter, C. J. (2019). Commonly used insect repellents hide human odors from Anopheles mosquitoes. Current Biology, 29(21), 3669-3680.

Alagumalai, A. (2015). Combustion characteristics of lemongrass (Cymbopogon flexuosus) oil in a partial premixed charge compression ignition engine. Alexandria Engineering Journal, 54(3), 405-413.

Al-Sarar, A. S., Hussein, H. I., Abobakr, Y., Al-Zabib, A. A., \& Bazeyad, A. Y. (2020). Mosquitocidal and repellent activities of essential oils against Culex pipiens L. Entomological Research, 50(4), 182-188.

Bali, G. K., \& Kaur, S. (2013). Phenoloxidase activity in haemolymph of Spodoptera litura (Fabricius) mediating immune responses challenge with entomopathogenic fungus, Beauveria bassiana (Balsamo) Vuillmin. Journal of Entomology and Zoology Studies, 1(6), 118-123.

Banthorpe, D. V., \& Charlwood, B.V. (1980). The terpenoids. In: Encyclopedia of Plant Physiology. Bell, E.A. and Charlwood, B.V. Eds. Berlin, Heidelberg, New York, Springer. p. 185

Banthorpe, D. V., Charlwood, B. V., \& Francis, M. J. O. (1972). Biosynthesis of monoterpenes. Chemical reviews, 72(2), 115-155.

Brari, J., \& Thakur, D. R. (2015). Fumigant toxicity and cytotoxicity evaluation of monoterpenes against four stored products pests. International Journal of Development Research, 5, 5661-5667.

Brown, J. E., Cook, R. J., Lipton, A., \& Coleman, R. E. (2012). Serum lactate dehydrogenase is prognostic for survival in patients with bone metastases from breast cancer: a retrospective analysis in bisphosphonate-treated patients. Clinical Cancer Research, 18(22), 6348-6355.

Chandrashekar, K. S., \& Prasanna, K. S. (2010). Analgesic and anti-inflammatory activities of 
the essential oil from Cymbopogon flexuosus. Pharmacognosy Journal, 2(14), 23-25.

Croteau, R. (1988). Catabolism of monoterpenes in essential oil plants. Developments in food science.

Croteau, R. (1987). Biosynthesis and catabolism of monoterpenoids. Chemical Reviews, 87(5), 929-954.

Devi, M. A., Sahoo, D., Singh, T. B., \& Rajashekar, Y. (2019). Toxicity, repellency and chemical composition of essential oils from Cymbopogon species against red flour beetle Tribolium castaneum Herbst (Coleoptera: Tenebrionidae). Journal of Consumer Protection and Food Safety, 1-11.

Dhinesh, B., Lalvani, J. I. J., Parthasarathy, M., \& Annamalai, K. (2016). An assessment on performance, emission and combustion characteristics of single cylinder diesel engine powered by Cymbopogon flexuosus biofuel. Energy Conversion and Management, 117, 466-474.

Döll-Boscardin, P. M., Sartoratto, A., Sales Maia, B. H. L. D. N., Padilha de Paula, J., Nakashima, T., Farago, P. V., \& Kanunfre, C. C. (2012). In vitro cytotoxic potential of essential oils of Eucalyptus benthamii and its related terpenes on tumor cell lines. Evidence-Based Complementary and Alternative Medicine, 2012.

Eden, W. T., Alighiri, D., Supardi, K. I., \& Cahyono, E. (2020). The mosquito repellent activity of the active component of air freshener gel from Java Citronella oil (Cymbopogon winterianus). Journal of parasitology research, 2020.

El Mokhtari, K., M'hammed, E. L., Talbi, M., Hajji, L., \& El Brouzi, A. (2020). Chemical composition and insecticidal activity of Anacyclus pyrethrum essential oil from the Bensliman area against Culex pipiens. Mediterranean Journal of Chemistry, 10(1), 1321.

Feroz, A. (2020). Efficacy and cytotoxic potential of deltamethrin, essential oils of Cymbopogon citratus and Cinnamonum camphora and their synergistic combinations against stored product pest, Trogoderma granarium (Everts). Journal of Stored Products Research, 87, 101614.

Gaire, S., Scharf, M. E., \& Gondhalekar, A. D. (2019). Toxicity and neurophysiological impacts of plant essential oil components on bed bugs (Cimicidae: Hemiptera). Scientific 
reports, 9(1), 1-12.

Ganjewala, D. (2009). Cymbopogon essential oils: Chemical compositions and bioactivities. International journal of essential oil therapeutics, 3(2-3), 56-65.

Ganjewala, D., \& Gupta, A. K. (2013). Lemongrass (Cymbopogon flexuosus Steud.) Wats essential oil: overview and biological activities. Recent Progress in Medicinal Plants, 37, 235-271.

Ganjewala, D., \& Luthra, R. (2007a). Essential oil biosynthesis and metabolism of geranyl acetate and geraniol in developing Cymbopogon flexuosus (Nees ex Steud) Wats Mutant cv. GRL-1 Leaf. Am J Plant Physiol, 2, 269-75.

Ganjewala, D., \& Luthra, R. (2007b). Inhibitors of essential oil biosynthesis in Cymbopogon flexuosus Nees ex. Steud. mutant cv. GRL-1 leaves. Am J Plant Physiol, 2, 227-32.

Gräwert, T., Groll, M., Rohdich, F., Bacher, A., \& Eisenreich, W. (2011). Biochemistry of the non-mevalonate isoprenoid pathway. Cellular and molecular life sciences, 68(23), 37973814.

Hamid, A. A., Aiyelaagbe, O. O., \& Usman, L. A. (2011). Essential oils: its medicinal and pharmacological uses. International journal of Current research, 33(2), 86-98.

Hassoun, A., \& Çoban, Ö. E. (2017). Essential oils for antimicrobial and antioxidant applications in fish and other seafood products. Trends in Food Science \& Technology, 68, 26-36.

Huang, Q., Liu, D., Xin, B., Cechner, K., Zhou, X., Wang, H., \& Zhou, A. (2016). Quantification of monosialogangliosides in human plasma through chemical derivatization for signal enhancement in LC-ESI-MS. Analytica Chimica Acta, 929, 3138.

Huong, L. T., Hung, N. H., Dai, D. N., Tai, T. A., Hien, V. T., Satyal, P., \& Setzer, W. N. (2019). Chemical Compositions and Mosquito Larvicidal Activities of Essential Oils from Piper Species Growing Wild in Central Vietnam. Molecules, 24(21), 3871.

Isman, M. B. (2006). Botanical insecticides, deterrents, and repellents in modern agriculture and an increasingly regulated world. Annu. Rev. Entomol., 51, 45-66.

Kain, P., Boyle, S. M., Tharadra, S. K., Guda, T., Pham, C., Dahanukar, A., \& Ray, A. (2013). 
Odour receptors and neurons for DEET and new insect repellents. Nature, 502(7472), 507-512.

Kakarla, S., \& Ganjewala, D. (2009). Antimicrobial activity of essential oils of four lemongrass (Cymbopogon flexuosus Steud) varieties. Med. Aromat. Plant Sci. Biotechnol, 3(1), 10709.

Kalita, M. K., \& Devi, D. (2016). Immunomodulatory effect of chlorpyrifos formulation (Pyrifos-20 EC) on Philosamia ricini (Lepidoptera: Saturniidae). J. Entomol. Zool. Stud., 4(6), 26-31.

Kalita, M. K., Haloi, K., \& Devi, D. (2017). Cypermethrin formulation (Ustad-10 EC) induces genotoxicity via apoptosis, affects nutritional physiology, and modulates immune response in silkworm Philosamia ricini (Lepidoptera: Saturniidae). Journal of Economic Entomology, 110(3), 1010-1024.

Kapur, A., Felder, M., Fass, L., Kaur, J., Czarnecki, A., Rathi, K., Zeng, S., Osowski, K. K., Howell, C., Xiong, M. P., Whelan, R. J., \& Patankar, M.S. (2016). Modulation of oxidative stress and subsequent induction of apoptosis and endoplasmic reticulum stress allows citral to decrease cancer cell proliferation. Scientific reports, 6, 27530.

Kuzuyama, T. (2002). Mevalonate and nonmevalonate pathways for the biosynthesis of isoprene units. Bioscience, biotechnology, and biochemistry, 66(8), 1619-1627.

Li, M., Liu, B., Bernigaud, C., Fischer, K., Guillot, J., \& Fang, F. (2020). Lemongrass (Cymbopogon citratus) oil: A promising miticidal and ovicidal agent against Sarcoptes scabiei. PLOS Neglected Tropical Diseases, 14(4), e0008225.

Maffei, M., Codignola, A., \& Fieschi, M. (1988). Photosynthetic enzyme activities in lemongrass cultivated in temperate climates. Biochemical systematics and ecology, 16(3), 263-264.

Manh, H. D., \& Tuyet, O. T. (2020). Larvicidal and Repellent Activity of Mentha arvensis L. Essential Oil against Aedes aegypti. Insects, 11(3), 198.

Manh, H. D., Hue, D. T., Hieu, N. T. T., Tuyen, D. T. T., \& Tuyet, O. T. (2020). The Mosquito Larvicidal Activity of Essential Oils from Cymbopogon and Eucalyptus Species in Vietnam. Insects, 11(2), 128.

Meena, S., Kumar, S. R., Venkata Rao, D. K., Dwivedi, V., Shilpashree, H. B., Rastogi, S., ... 
\& Nagegowda, D. A. (2016). De novo sequencing and analysis of lemongrass transcriptome provide first insights into the essential oil biosynthesis of aromatic grasses. Frontiers in plant science, 7, 1129.

Moore, S. J. (2014). Plant-based insect repellents. In: Debboun M, Frances SP Strickman D (eds), Insect repellents handbook, 2nd edn, CRC Press, Boca Raton, pp 179-213

Muturi, E. J., Selling, G. W., Doll, K. M., Hay, W. T., \& Ramirez, J. L. (2020). Leptospermum scoparium essential oil is a promising source of mosquito larvicide and its toxicity is enhanced by a biobased emulsifier. Plos one, 15(2), e0229076.

Ngongang, M. D. T., Eke, P., Sameza, M. L., Djiéto, C. L., \& Boyom, F. F. (2019). GC/MS profiling and insecticidal potential of essential oils from Thymus vulgaris (Lamiaceae) and Cymbopogon citratus (Poaceae) against tomato borer, Tuta absoluta.

Pavela, R., \& Benelli, G. (2016). Essential oils as ecofriendly biopesticides? Challenges and constraints. Trends in plant science, 21(12), 1000-1007.

Politi, F. A., Nascimento, J. D., da Silva, A. A., Moro, I. J., Garcia, M. L., Guido, R. V., Pietro, R. C., Godinho, A. F., \& Furlan, M. (2017). Insecticidal activity of an essential oil of Tagetes patula L.(Asteraceae) on common bed bug Cimex lectularius L. and molecular docking of major compounds at the catalytic site of ClAChE1. Parasitology research, 116(1), 415-424.

Price, D. N., \& Berry, M. S. (2006). Comparison of effects of octopamine and insecticidal essential oils on activity in the nerve cord, foregut, and dorsal unpaired median neurons of cockroaches. Journal of insect physiology, 52(3), 309-319.

Qari, S. H., Nilly, A. H., Abdel-Fattah, A. H., \& Shehawy, A. A. (2017). Assessment of DNA damage and biochemical responses in Rhyzopertha dominica exposed to some plant volatile oils. Journal of Pharmacology and Toxicology, 12(2), 87-96.

Rajashekar, Y., Raghavendra, A., \& Bakthavatsalam, N. (2014). Acetylcholinesterase inhibition by biofumigant (Coumaran) from leaves of Lantana camara in stored grain and household insect pests. BioMed Research International, 2014.

Rattan, R. S. (2010). Mechanism of action of insecticidal secondary metabolites of plant origin. Crop protection, 29(9), 913-920.

Richard, S. B., Bowman, M. E., Kwiatkowski, W., Kang, I., Chow, C., Lillo, A. M., Cane, D. 
E., \& Noel, J. P. (2001). Structure of 4-diphosphocytidyl-2-C-methylerythritol synthetase involved in mevalonate-independent isoprenoid biosynthesis. Nature structural biology, 8(7), 641-648.

Rohmer, M. (1999). The discovery of a mevalonate-independent pathway for isoprenoid biosynthesis in bacteria, algae and higher plants. Natural product reports, 16(5), 565-574.

Sanches, L. J., Marinello, P. C., Panis, C., Fagundes, T. R., Morgado-Díaz, J. A., de-FreitasJunior, J. C. M., ... \& Luiz, R. C. (2017). Cytotoxicity of citral against melanoma cells: The involvement of oxidative stress generation and cell growth protein reduction. Tumor Biology, 39(3), 1010428317695914.

Scalerandi, E., Flores, G. A., Palacio, M., Defagó, M. T., Carpinella, M. C., Valladares, G., ... \& Palacios, S. M. (2018). Understanding synergistic toxicity of terpenes as insecticides: Contribution of metabolic detoxification in Musca domestica. Frontiers in plant science, $9,1579$.

Sharma, P. R., Mondhe, D. M., Muthiah, S., Pal, H. C., Shahi, A. K., Saxena, A. K., \& Qazi, G. N. (2009). Anticancer activity of an essential oil from Cymbopogon flexuosus. Chemico-biological interactions, 179(2-3), 160-168.

Singh, K. D., Labala, R. K., Devi, T. B., Singh, N. I., Chanu, H. D., Sougrakpam, S., ... \& Rajashekar, Y. (2017). Biochemical efficacy, molecular docking and inhibitory effect of 2, 3-dimethylmaleic anhydride on insect acetylcholinesterase. Scientific reports, 7(1), 111.

Solomon, B., Gebre-Mariam, T., \& Asres, K. (2012). Mosquito repellent actions of the essential oils of Cymbopogon citratus, Cymbopogon nardus and Eucalyptus citriodora: evaluation and formulation studies. Journal of Essential Oil Bearing Plants, 15(5), 766773.

Srivastava, V., Dubey, S., \& Mishra, A. (2013). A review on lemon grass: agricultural and medicinal aspect. International Research Journal of Pharmacy, 4(8), 42-44.

Suwannayod, S., Sukontason, K. L., Pitasawat, B., Junkum, A., Limsopatham, K., Jones, M. K., ... \& Thavara, U. (2019). Synergistic toxicity of plant essential oils combined with pyrethroid insecticides against blow flies and the house fly. Insects, 10(6), 178.

Swamy, M. K., Akhtar, M. S., \& Sinniah, U. R. (2016). Antimicrobial properties of plant 
essential oils against human pathogens and their mode of action: an updated review. Evidence-Based Complementary and Alternative Medicine, 2016.

Tak, J. H., \& Isman, M. B. (2016). Metabolism of citral, the major constituent of lemongrass oil, in the cabbage looper, Trichoplusia ni, and effects of enzyme inhibitors on toxicity and metabolism. Pesticide biochemistry and physiology, 133, 20-25.

Tak, J. H., Jovel, E., \& Isman, M. B. (2016). Contact, fumigant, and cytotoxic activities of thyme and lemongrass essential oils against larvae and an ovarian cell line of the cabbage looper, Trichoplusia ni. Journal of pest science, 89(1), 183-193.

Tisserand, R., \& Young, R. (2013). Essential oil safety-e-book: A guide for health care professionals. Elsevier Health Sciences.

Vergis, J., Gokulakrishnan, P., Agarwal, R. K., \& Kumar, A. (2015). Essential oils as natural food antimicrobial agents: a review. Critical reviews in food science and nutrition, 55(10), 1320-1323.

Zheljazkov, V. D., Cantrell, C. L., Astatkie, T., \& Cannon, J. B. (2011). Lemongrass productivity, oil content, and composition as a function of nitrogen, sulfur, and harvest time. Agronomy Journal, 103(3), 805-812. 